\title{
XLVI. Experiments relative to coals and cokes obtained from wood and pit-coal
}

\section{David Mushet Esq.}

To cite this article: David Mushet Esq. (1808) XLVI. Experiments relative to coals and cokes obtained from wood and pit-coal , Philosophical Magazine Series 1, 32:127, 309-315, DOI: $10.1080 / 14786440808562801$

To link to this article: http://dx.doi.org/10.1080/14786440808562801

曲 Published online: 18 May 2009.

Submit your article to this journal $\sqsubset \pi$

Џ Article views: 2

Q View related articles $\sqsubset$ 
XI.VI. Fxperiments relative to Coals and Cokes obtained from Wood and Pit-coal. By David.Mushet, Esq.

I

NEED hardly remark, that charcoal is composed of pure carbon, or diamond, combincd with a certain portion of oxygen-and is therefore considered as an oxide. Oxides of carbon are furnished in greater or less portions, and of various degrees of purity, by every substance in the vegetable kingdom. Almost every substance in the animal œconomy yields it, and frequently in a state of comparative purity. In the mineral kingdom, in pit-coal, plumbago, mineral pitch, naphtha, \&c., we find it bearing a greater proportion to the other ingredients of the compound than either in the animal or vegetable departments.

The proportion of oxygen united with carbon to form charcoals has not hitherto been ascertained; but from the great dose necessary to form carbonic acid, it is probable that some oxides contain from 30 to 50 per cent.

This will be made to appear highly probable, from the combustion or distillation of different substances in close vessels. No direct experiment has been hitherto made to ascertain the precise quantity of oxygen united to the coaly residue obtained in the preparation of coke, charcoal, or any species of coal; but by a comparison of their carhonating effects, when applied as agents in the dry way of experiment, or even upon the more enlarged scale of manufacture, we may form a pretty correct estimate of their real value, or their approximation to the state of diamond.

From numerous experiments which $I$ have made, it appears to me highly probable, that the oxide of diamond exists ready formed in almost every substance that yields a carbonaceous residuum. It has been conceived by some, that the oxide is formed in consequence of the ignition of the substance from which charcoal is meant to be obtained, by the combination of the oxygen liberated from the atmospheric air, or from surrounding bodies; and that, according to the quantity of oxygen combined with the matter of carbon, the resulting oxide would be more or less dcbased. It is 
probable that this takes place to a certain extent, and that all carbonaceous matter prepared in contact with atmospheric air is inferior in point of purity, or, in other words, is not so highly de-oxygenalcd as that prepared in close vessels. I do not find, however, that, by having recourse to close vessels where there is no contact of atmospheric air, the resulting product is materially altered as to colour and general appearance, or that the oxide of diamond apparently exists in a state of diminution. Its carbonating effects, however, become wonderfully changed by such a plan of procedure; and subsequent experimest, in various stages, develops many characteristics not unworthy of an approach to the state of diamond.

This change of quality may arise from another suurce than simple distillation in close vessels, and the prevention of the contact of external air.

If the heat of the distillation is urged beyond a dull red colour, or even continued longer at the usual temperature, the oxide begins to de-oxidate itself, and the product will be found materially cbanged as to its usual affinities. It will be found more difficult to ignite in common open air. Its combustion unless impelled with mechanical violence will move on sluggishly, and under every circumstance a higher temperature and longer contact will be requisite, to effect an union with its usual relations. The extent of carbonaceous principle arising from a given weight will, however, be increased in the same proportion as the substance has been de-oxidated. A greater quantity of carbonic acid gas will be obtained from the same weight of oxide, and of course a greater quantity of carbon set free.

It is difficult to say to what extent this de-oxidizing principle might be carried. In heats of 160 and $170^{\circ}$ of Wedgwood, the increased density of the carbon, particularly if in the state of powder, and the uncommon depth of lustre which the black assumes, are evidences that some material change has passed upon the arrangement of its constituent parts. There can, however, be no loubt that there exist certain fixed limits, unless a third affinity be interposed, beyond which carbonaceous matter ceases to de-oxidate it- 
self : or should its operation continue in temperatures when we cease to perceive any material change, its progress most probably would be so slow as to require ages before the second portion of oxygen was set free. This last will be regulated by the nature of the affinities betwixt carbon and oxygen, and the progress of their action upon each other during the exposure.

If the affinity of de-oxidation is supposed once to be established, and the carbonaceous matter to be approaching to the state of diamond, by sacrificing part of itself in combination with the oxygen, its tendency to do so will be diminishing in the ratio of its continuance, unless some new action, by increase of temperature, affinity or otherwise, be excited. The ultimate period of de-oxidation will therefore most likely be retarded by both a want of time and means. The difficulty arising from the former, and want of temperature to extract or give both an additional affinity that would clear the oxide of its second and third portions of oxygen, are evidently so great as to leave little hope of forming any thing in this way purer than a highly incombustible coal.

The combustion of wood or of pit-coal to form coke or charcoal may be considered as a principal step towards deoxidation. In the natural state of wood and pit-cod, the carbonaceous matter appears to be highly surcharged with oxygen, which is in part carried off in burning.

If the ignition has been performed in open fires exposed to external air, a greater portion of the original oxygen will remain fixed. On the contrary, when distillation is performed so as to secure the product from the contact of atmospheric air, the portion of carbonaceous matter, which in all cases is unavoidably lost, is here combined with the oxygen of the oxide, which is left in a state of comparative purity, in place of being carried off in simple combustion by the external air.

Every oxide of carbon that has hitherto been cxamincd contains a portion of foreiga matter in the state of earths or salts, and it appears by experiment that even the diamond is not entirely free from such an alloy. 
100 parts of oxide of the following substances from the vegetable kingdom have been fuund thus alloyed:

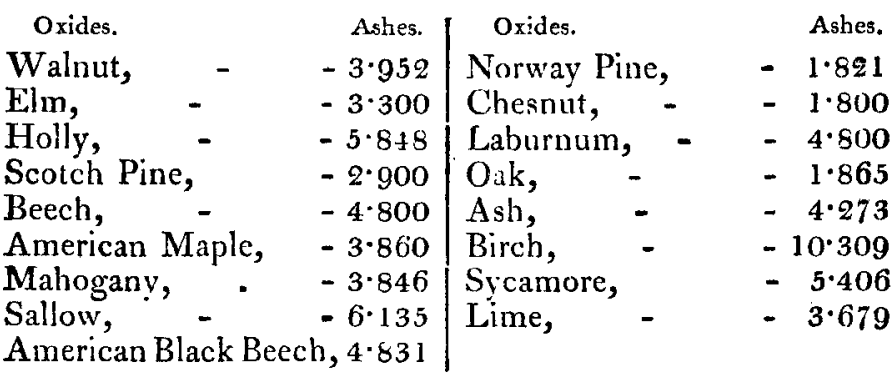

Pit-coal affords, after burning or distillation, a large portion of coke or oxide of carbon. This, in like manner with that procured from wood, contains various proportions of alloy.

The coals found in the extensive coal country around Glasgow are divided into five workable measures, No. 1, 2, $\mathbf{3 , 4}, \mathbf{5}$. These are possessed of various local names, and their analyses in different places give different results. Even the same measure always contains two and not unfrequently four different qualities, possessed of parts dissinilarly compounded, and yielding different products when used as agents in experiments. Under such circumstances, a classification of these various qualities will serve better than an enumeration of every particular measure, to convey an idea how these oxides are compounded.

The Scotch coals in general, in that quarter, may be shortly arranged under soft, mixed, and hard coals.

The soft may again be divided into free coal, i.e. coal that burns in the fire without welding or caking; and into coal that in burning adheres more or less together, or that enters into a bituminous kind of fusion and forms a firm compact cinder.

Each of these varieties again yields a quantity of ashes, which in colour may proceed from pure white to deep brownish red. This distinction is of the utmost importance, and ought to be the subject of another division. So that in order to furm a correct idea of the nature of the resulting oxide 
oxide from each of these varieties, the following arrangement will be necessary :

$$
\begin{aligned}
& \text { 1st, soft coal free, white ash. } \\
& 2 \mathrm{~d}, \square \text {, red ash. } \\
& 3 \mathrm{~d}, \square \text { caking, white ash. }
\end{aligned}
$$

The following are the results of five specimens analysed from the 1st measure of the Great Coal Field around Glasgow, distinguished by the following coal names; commissary coal, upper coal, double coal, \&c., corresponding to No. 1.-

100 parts of nxide of-

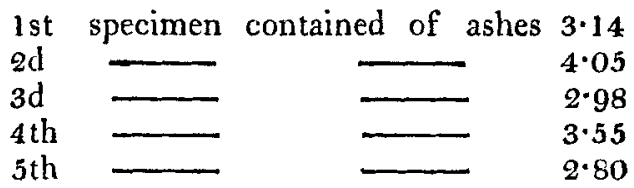

The four following varieties are extracted Trom a number of results, of which they may serve as an average ; many of them, taken from the same measure, and even in contact with the former. These correspond with variety No. 2. 100 parts of oxide of-

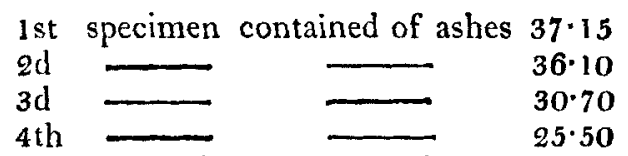

The following results are taken from experiments with welding coals, No. 3. In general these coals leave a red or brownish-red ash. Those found in Yorkshire, and used at the furnaces for iron-making, contain the whitest ash.

100 parts of oxide of-

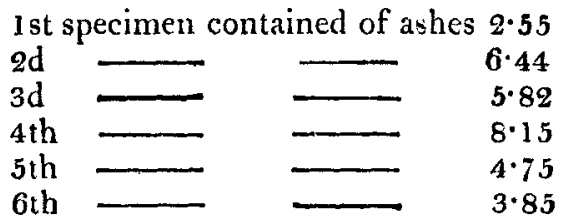

No. 4, or that variety of soft coal that welds and leaves an ash of a red colour, or of any intermediate shade betwixt a light ochrey brown and a deep red brown, contains a greater variety of alloy than any other description of coal.

The coals got at the Newcastle and Sunderland collieries are chiefly 
chiefly of this description, and yield ashes of almost every shade from light brown to deep brown red.

The following results will show the immense variety of alloy that is found in oxides taken from this class.

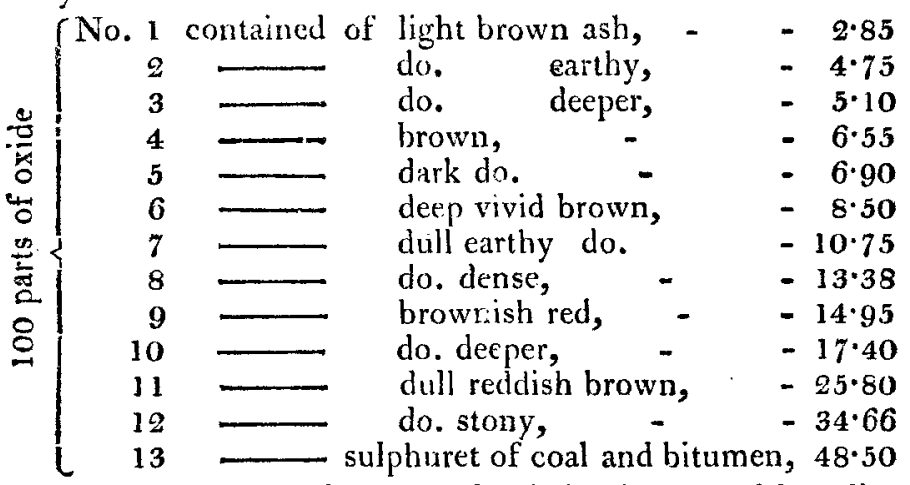

The $2 \mathrm{~d}$, or mixed class of coals, being in general less dissimilar to each other, afford a less variety of alloy. The ashes of this kind of coal are in common specifically lighter than those of any other class, and vary from a blueish white to a primrose colour.

The purity of the oxides obtained from it may be gathered from the following results :

100 parts of oxide-

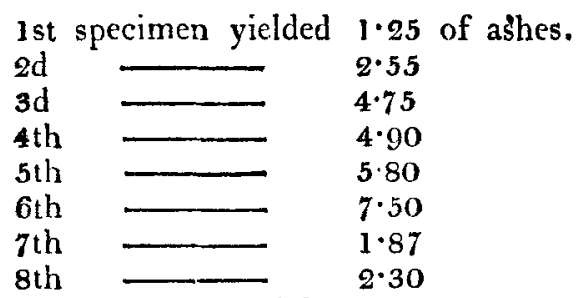

The $3 \mathrm{~d}$, or hard coals, judging from appearance and from the analysis of their oxides, may be divided into three varieties; candle or cannel coal, hard, and stony hard.

100 parts of the oxides of candle coal yielded of alloy as follows :

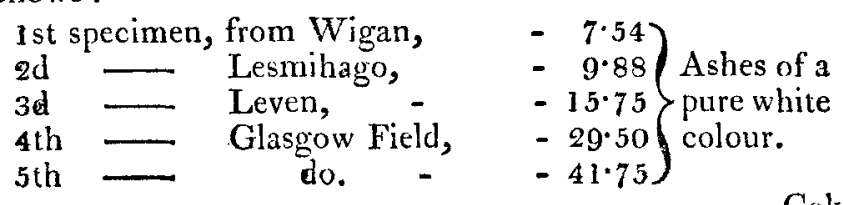


Coke, or oxide of carbon, obtained from hard coal, is generally combined with a pure white ash, and frequently possessed of considerable density. The quantity of this alloy may be estimated from the following results from 100 parts of each :

Jst specimen of cokes contained of ashes 6.78

$2 \mathrm{~d}$

$3 \mathrm{~d}$

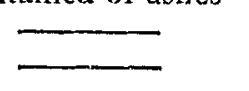

$8 \cdot 25$

$7 \cdot 50$

4th $=\quad-\quad 9 \cdot 54$

5 th - - $1,1 \cdot 78$

6 th - 12.12

That particular variety of coal, which has been described as belonging to the hard coal class, under the name of stony hard, after combustion leaves a white stone covered with very fine white ashes of the same colour. In many cases the proportion that the alloy bears to the carbonaceous matter is equal, and sometimes greater.-One hundred parts of colses-

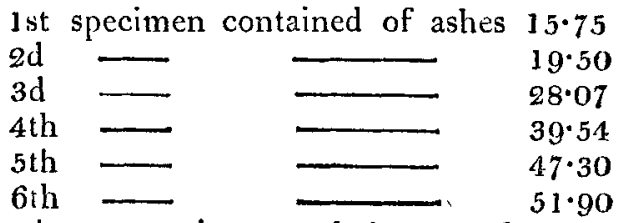

Besides these experiments relative to coals and cokes produced from wood and pit-coal, I have performed a number of others upon various substances, animal and vegetable, with a view to produce oxide of carbon, to form a general estimate of their comparative merits. Some of these I shall send you for a future number of the Philosophical Magazine.

XLVII. Some interesting Additions to the Natural History of Falco cyaneus and pygargus, together with Remarks on some other British Birds. By George MonTAGU, Esg. F.L.S.*

Falco cyaneus.

Ind. Orn. i. p. 39. 94.

Hen Harrier. Lath. Syn.

That the natural history of a bird indigenous to this country, and by no means uncommon, should have so long con-

* From the Transacticns of the Linnaan Society, vol. ix.

tinued 